\title{
Investigating the Effect of Diet Therapy on Reducing Women's Overall Self-Esteem
}

\author{
Moghadam, Safoura $^{1}{ }^{*}$, Niknejadi, Farzaneh ${ }^{2}$, Irvani, Mohammad-Reza ${ }^{3}$
}

\section{ABSTRACT}

Overweight and obesity make physical and psychological complications for people. In this regard, Low self-esteem will be the most important psychological condition. This study investigates the effect of diet therapy of women (reduction in body mass) on reducing their overall self-esteem. The population of the study was the women who were referred to diet therapy clinic in Isfahan (2014). The number of 30 subjects among them was selected. In order to measure women's self-esteem, Cooper Smith Self-Esteem Test is used for demographic data, a self-measured questionnaire was used. Analysis of the data in the study was descriptive and inferential statistics. The results show that there is a significant difference between the selfesteem of women in four steps that indicate an effective diet therapy (reduction of body mass) on reducing self-esteem of women between the four stages It means that it leads to low self-esteem in women's diet therapy $(0.05>\mathrm{P})$.

Keywords: Obesity, Diet Therapy, Women, Self-esteem

OBJECTIVES: Overweight and obesity are defined as a risk factor for health, with high fat and abnormal problem (World Health organization, 2011) and due to the lack of variety, proportion and balance between food diet, genetic problems, and environmental factors of metabolic diseases such as thyroid, nervous and muscular disorders, bone and joint diseases, endocrine disorders, certain medications and psychological factors to create (Mokdad et al., 2000). Perception of the person from their body is leading to estimate more or less size of the body and emotional-cognitive changes due to dissatisfaction and concern related to form of body. Body image is a mental structure and a central concept to the health psychologists (Grogan, 2006). The prevalence of body dissatisfaction is a major concern for numerous people because of mental disorders such as low self-esteem, depression, social anxiety, eating disorders, sexual dysfunction and diseases linked to deformities of the body (Prozinsky, 1990; Nye, 2006). In general, overweight and obesity make physical and psychological complications for people with this condition. Low self-esteem will be the most important psychological condition. Basically, self-esteem is driven from the sense of worth and confidence inside a person against him or

\footnotetext{
${ }^{1}$ M.Sc. in Counseling and Guidance, Islamic Azad University of Khomeini-Shahr, Isfahan, Iran

${ }^{2}$ PHD in Philosophy-Pedagogy and Education Development, Assistant Professor, Islamic Azad University of Khomeini-Shahr, Isfahan, Iran

${ }^{3}$ PHD in Social Working, Assistant Professor, Islamic Azad University of Khomeini-Shahr, Isfahan, Iran *Corresponding Author (C) 2015 I M Safoura, N Farzaneh, I Reza; licensee IJIP. This is an Open Access Research distributed under the terms of the Creative Commons Attribution License (http://creativecommons.org/licenses/by/2.0), which permits unrestricted use, distribution, and reproduction in any Medium, provided the original work is properly cited.
} 
herself. In fact, self-esteem, according to Cooper Smith is a personal judgment of selfworthwhile which represents the person's attitude toward the capabilities and the importance of the success and self-evaluation. Essentially self-esteem is a personality trait rather than a specific attitude for special occasions (Vosk, 2000). In general, obese or overweight individuals may lose their self-esteem in some conditions (Grogan, 2006; Robin Stein, 2005). Most of the young women lost their self-esteem and feel more judged by others are (Cash et al., 1986).

In this regard, due to the great influence of weight gain and obesity on the psychological and personality traits of different people, especially women, such research raises fundamental questions that whether women's diet treatment reduce their self-esteem.

Importance and Necessity of Research: The researches have shown that the differences in perception between body image and ideal body image for individuals could be leading to considerable dissatisfaction (Ferrari et al., 2010). In addition, estimates of overweight, obesity and morbid obesity ( $40 \leq \mathrm{BMI})$ have indicated the occurrence rates of $26.6 \%, 10.8 \%$ and $3.4 \%$ (Baghaiei, 2008). Results of findings are a warning in the field of high frequency and abdominal obesity in Iran. Unhealthy lifestyle habits have an important role in the development of the public health problem in our society (Delavari et al., 2007). Studies show that increased body mass index in adolescent girls tend to have the consequences such as weight loss, decreased sense of self-worth, deficiency, sparingly in the body by eating food, eating more and concerns with weight gain and diet (Vandrol, 2000). This process could be the background of diet which, in turn, is considered one of the main contributing factors in mental disorders (Stice, 2001). Regarding the studies conducted depression due to the obesity in daily related activities of living women causes many difficulties in their responsibilities and in some cases even it increases the risk of suicide. During the course of studies, an increase of 10 units in BMI has increased the risk of suicidal thoughts and attempts among women (Hosty, 2000). Studies show that the individuals whom prestige, acceptance by the community and others have the most important role on selfesteem, a bad reputation could be obesity and reduce their self-esteem (Crocker and Wolfe, 2001). For this reason, understanding the impact of diet is very important on mental disorders and personality, especially the loss of confidence.

The purpose of the study: Investigating the impact of diet therapy of women (reduction in body mass) on reducing their overall self-esteem

Hypothesis: Diet therapy (body mass reduction) is effective in reducing self-esteem of women.

Background Research: Given the importance of the issue and its impact on personal and social characteristics, the extensive studies have been conducted in this area. For instance, Grosse et al. (2013) in their study of satisfaction of the body and its relationship has been studied with some mental health components (depression, self-esteem) in pregnant women. The results have expressed $48.7 \%$ of body dissatisfaction and $30 \%$ of the different degrees of depression. There is a significant and negative relationship between depression, a good impression of the body and a significant and positive relationship between self-esteem and body satisfaction. The research of 
Golparvar et al. (2007) examines the relationship of overweight in women referred to weight loss centers with self-esteem, depression, lifestyle and physical (physical self-concept) in Isfahan. The results showed that overweight has a significant relationship with depression, spiritual weight and face evaluation. In regression analysis, subjective weight and fitness orientation (both self-physical subscales) can be a significant predictor of overweight. In stepwise regression analysis, body weight, evaluation of fitness and appearance can be a significant predictor of overweight. In other research Mohammadi and Sajadinezhad (2007) studied psychometric indicator of body images, body mass index (BMI) and Pierre image, body image dissatisfaction because there is a relationship between self-esteem and body image dissatisfaction. Also Bokingam (2005) in a study entitled "self-esteem as a modulator variable on social comparison on body image of women" showed that women have lower self-esteem than others, those who think a weak body and its comparison with others has always been in the process of evaluating their abilities and their bottom. Kaferi (2002) in their study found that body dissatisfaction in boys in particular is accompanied with high levels of depression and low self and life satisfaction.

\section{METHOD:}

\section{Study population:}

The research was consisted of women who sought diet therapy (reduction in body mass) referred into Nutrition and Diet Therapy Clinic of Dr. Mohammadi in Isfahan (2014).

Sample and Sampling: The number of 30 subjects was randomly selected as a sample size since one month before implementing the study in the nutrient clinic in Isfahan. In this study, 30 women aged 18 to 45 years old were evaluated with a mean body mass index $(25 \leq \mathrm{BMI})$. Weight and self-esteem were measured in these patients. Sample for 4 months in the period received four diet plans and diet therapy were studied. According to the selection criteria mentioned above, contributing the participants in the diet therapy program is from the criteria that their two session-absence leads to eliminate them.

\section{Research Instrument:}

In order to measure women's self-esteem, Cooper Smith Self-Esteem Test was used. Also the demographic data were collected related to marital status, education level, employment status and age using a self-administered questionnaire.

\section{Validity and Reliability of Study Instrument:}

Test reliability has been reviewed and approved on several occasions. Cooper Smith and colleagues (quoted by Neisi and ShahniYeylagh, 2002) reported the test-retest reliability of the questionnaire 0.88.Also the validity of ShahnyYeilagh, Shekarkan, Michaeli and Haghighi's questionnaire (2007) was obtained by both Bisection method and Cronbach's alpha 0.73. 


\section{RESULTS}

Table (1) Comparison of self-esteem in four steps

\begin{tabular}{ccc} 
& Average & Standard deviation \\
\hline First stage & 31.26 & 3.96 \\
Second phase & 26.20 & 5.96 \\
Third stage & .2623 & 5.60 \\
Fourth stage & 23.46 & 4.16 \\
\hline
\end{tabular}

Based on the table (1) Average self-esteem scores were obtained at the first stage, 31.26, second stage 26.20, third stage, 26.23 and fourth stage 23.46 .

Table 2 showed the test results of sufficient correlation between the dependent variable.

Table (2) Test results sufficient correlation between the dependent variables

\begin{tabular}{cccc}
\hline Ratios & Chi & Df & Sig \\
\hline 0.000 & 14.620 & 9 & 0.102 \\
\hline
\end{tabular}

Table (3) Mauchly test

\begin{tabular}{ccccc}
\hline & Mauchly & Chi-square & Degree of freedom & Significant level. \\
\hline Self-esteem & 0.851 & 4.48 & 5 & 0.483 \\
\hline
\end{tabular}

Based on the table (3) Muachly test's P value which is equal to 0.483 shows covariance tests equal and can be a prerequisite to the table with the default equality analysis of covariance (Spheircity)

Table (4) Analysis of variance with repeated measures of self-esteem

\begin{tabular}{ccccccc}
\hline \multirow{2}{*}{ Effect } & $\begin{array}{c}\text { Multivariate } \\
\text { test }\end{array}$ & Value & $\begin{array}{c}\text { F } \\
\text { statistics }\end{array}$ & $\begin{array}{c}\text { Confidence } \\
\text { level }\end{array}$ & $\begin{array}{c}\text { Share my } \\
\text { ETA }\end{array}$ & $\begin{array}{c}\text { Ability } \\
\text { test }\end{array}$ \\
\hline \multirow{5}{*}{ Self-esteem } & Pillay effect & 0.701 & 21.081 & 0.001 & 0.710 & 1 \\
& Wilks Lambda & 0.299 & 21.081 & 0.001 & 0.701 & 1 \\
& Hotelling effect & 2.324 & 21.081 & 0.001 & 0.701 & 1 \\
& Maximum root & 2.342 & 21.081 & 0.001 & 0.701 & 1 \\
\hline
\end{tabular}

Table 4 shows the results of analysis of variance with repeated sizes regarding the inequality due to covariance matrix of effect Lambda Wilks. Therefore the results can be placed based on the hypothesis that the difference between the studied dependent variables (general self-esteem is accepted and it is concluded that there are significant differences in 4-folded stage self-esteem. 
Investigating the Effect of Diet Therapy on Reducing Women's Overall Self-Esteem

Table (5) Inter-group results of self-esteem test

\begin{tabular}{ccccccc}
\hline \multirow{2}{*}{ Effect } & Multivariate testing & Value & $\begin{array}{c}\text { F } \\
\text { statistics }\end{array}$ & $\begin{array}{c}\text { Confidence } \\
\text { level. }\end{array}$ & $\begin{array}{c}\text { Share my } \\
\text { ETA }\end{array}$ & $\begin{array}{c}\text { Ability } \\
\text { test }\end{array}$ \\
\hline \multirow{2}{*}{ Self- } & Equality of covariance & 952.292 & 15.390 & $0.001 / 0$ & 0.347 & 1 \\
esteem & Green House & 952.292 & 15.390 & $0.001 / 0$ & 0.347 & 1 \\
& Flat & 952.292 & 15.390 & $0.001 / 0$ & 0.347 & 0.996 \\
\hline
\end{tabular}

F statistics at $05 \geq \mathrm{P}$ was significant, so there was a significant difference between the mean of self-esteem in four steps.

\section{DISCUSSION}

As the results show that in the study population according to the results, significant differences between the self-esteem of women, there are four stages of symptoms due to diet therapy (reduction in body mass) on low self-esteem among women in four steps that the diet therapy leads to reduce self-esteem in women's $(0.05>\mathrm{P})$. The hypothesis was confirmed by the effective diet therapy (body mass reduction) on reducing self-esteem of women.

Related research has not found, the findings of this study with research of Gross et al (2013), Golparvar et al. (2007), Badyba et al. (2008) and Grant and Cash (2005) showed that the relationship between self-esteem, body size and body satisfaction was significantly positive but not consistent.

In order to confirm the findings of this study Mohammadi and Sajadinezhad (2007) and Cafri (2002) also showed that there was a relationship between low self-esteem and body image dissatisfaction.

The findings of the study can be explained by documents of Buckingham studies (2005) that said women have lower self-esteem than others, those who think poorly about their body and their comparison with others has always been in the process of low self-evaluation and their ability. The sensitivity of dissatisfaction with body image and physical appearance can be found in more severe cases of the dissatisfaction and low self-esteem.

\section{CONCLUSION}

This study suggests that in the diet therapy and followed stages women have faced to low selfesteem. Although based on previous studies it is expected that there is a relationship between different factors of body satisfaction and self-esteem and relationship satisfaction, but the diet therapy had a negative impact on self-esteem. This could be due to the effect of other factors that affect self-esteem more powerful. A significant reduction has been seen between self-esteem in different dimensions. In our society, peer groups, colleagues and acquaintances have a significant impact on satisfaction, as well as the activities of the deformation of the body, as when family members because of the weight and the physique taunt the women, when women are under pressure from friends, family and mass media to lose weight, and his wife and family 
and friends have a lean physique to deliver serious notifications about styles the negative image of women's bodies are appeared.

Women in this study were not happy about their body image and this has created the problems for them, because in the course of treatment and after the course, it leads to low self-esteem in them. The concern about the stability of the desired changes in the next phase of the diet therapy is the most important concerns for women. On the other hand there may be some people who are motivated by the changes in body image and body image is more favorable business participation in such activities. Additionally, self-esteem is driven from the self-assessment and one's grounds of social, physical, family and so on.

Suggestions: The results of diet therapy (body mass reduction) reduced self-esteem and its components in women. The goals and treatment plans should be in line with the growing importance of women's self-esteem. Psychologists and nutrition counselors should consider it to treat and reduce symptoms of obesity in women.

Due to easier access more women in the study take place. It is recommended that future studies in order to promote mental health, men are also involved in this study. Study on the women referred to a special clinic in the city recommended that the study is carried out in the province and the country.

\section{REFERENCES}

Baghaiei, M. (2008). Statistical analysis of the obesity crisis in Iran, Monthly social-scientific medication and therapy, 5th edition, 37: 36-59.

Bodiba. P., Madu, S.N, Ezeokana J.O. \&Nnedum. O.A. (2008).The relationship between body mass index and self-concept among adolescent blac female University students. Journal Curationis, Published in South Africa.

Bokingam, J.T. (2005). Self-esteem as a Moderator of the Effect SocialComparison on Women Body I.Journal of Social and ClinicalPsychology g1164-1187.

Cafri G. (2002). Strauss, Male body Imagesatisfaction and its relationship to well.Being using the somatomorphic matrix,International Journal of men's health,may, vol:53, Number20.

Cash, H. \&Prozinsky, N. (1990), Bodyimage: Development, deviance andchange, New York: Gulford press.

Cash, T. F.; Winstead, B.A. \&Janda, L.M.(1986). Body Image Survey Report:The Great American Shape-up, Psychology Today, April, 30-37.

Crocker. J. \& Wolfe. C.T. (2001). Contingencies of self-worth, Psyche Rev, 108: 593-623.

Delawari, A; Kelishadi, R., Alikhani, S.\&Alaeddin.P. (2007). The incidence of obesity and national lifestyle in Iran: results of the first national study of risk factors for non-epidemic diseases. The papers presented at the Congress of prevention and treatment of obesity in Iran, Institute of Endocrinology and Metabolism of University, Obesity therapy Association of ShahidBeheshti, Iran.

Ferreira.C., Pinto-Gouveia.J. \& Duarte.C. (2011).The validation of the body image acceptance and action.Questionnaire, exploring the moderator effect of acceptance on disordered eating, International Journalof Psychology and Psychological Therapy. Oct; 11(3): 327345. 
Golparvar. M. \&Rismanchian. B. (2007). The relationship among overweight and self-esteem, depression, lifestyle and physical in self-concept women at weight loss centers, Volume 1, No.32, pp.121-144

Grogan. S. (2006) . Body image and health: contemporaryperspectives. J Health Psyche, 11(4):523-30.

Grosse.B. \&Razavi.N. (2013). Relationship between depression and self-esteem and body image in pregnant women, Health and Development Journal, Vol. II / 2, pp.127-117.

Mohammadi, N. \&Sajadinezhad, M. (2007).Evaluating the psychometric questionnaire about the image and body mass index test, dissatisfaction of body image and self-esteem in adolescent girls. Psychological Studies, spring, 3 (3): Pp.199-83.

Mokdad. A.H., Serdula. M.k. \&Dietz.W.H. (2000). TheContinuing epidemic of obesity in the UnitedStates, J Am Med Association; 284: 1650-1651.

Nye. S. \& Cash, T.F. (2006). Outcomesof mineralization cognitive behavioralbody image therapy witheating disordered women treated in aprivate clinical practice",International journal of eatingdisorders, 39(1):31-40.

Stice.E. (2001). Risk factors for eating pathology: Recent advances and future directions. In: Stiegel-Moore RH, Smolak L, editors, Eating disorders, Innovative directions in research and practice. 